Received: 08-12-2020

(Date-Month-Year)
Revised: 05-04-2021

(Date-Month-Year)
Published: 30-04-2021

(Date-Month-Year)

\title{
MODEL INOVASI PEMBELAJARAN MAHASISWA BERKEBUTUHAN KHUSUS (MBK) BERBASIS VIDEO BERSUBTITLE
}

\author{
Faisal Estu Yulianto', Bambang Kurnadi², Hasan Basri ${ }^{3}$, Ukthi Raudhatul Jannah ${ }^{4}$, \\ Moh Zayyadi ${ }^{5}$ \\ ${ }^{1}$ Informatika, Universitas Madura, Indonesia \\ ${ }^{2}$ Peternakan, Universitas Madura, Indonesia \\ 3,4,5 Pendidikan Matematika, Universitas Madura, Indonesia \\ ${ }^{1}$ faisal.estu@unira.ac.id \\ ${ }^{2}$ kurnadi@unira.ac.id \\ 3hasan_basri@unira.ac.id \\ ukhti_math@unira.ac.id \\ 5zayyadi@unira.ac.id
}

\begin{abstract}
Abstrak: Penelitian ini bertujuan untuk mengembangkan model pembelajaran secara daring yang ramah dan cocok bagi mahasiswa sesuai dengan kebutuhan khusus. Pengembangan model berbasis video yang digunakan dalam penelitian ini adalah model Desain Pembelajaran ADDIE (Analysis-Design-Develop-Implement-Evaluate). desain produk ini diantaranya: (1) RPS; (2) Materi ajar; (3) Video Pembelajaran; dan (4) Evaluasi Pembelajaran. Teknik pengumpulan data yang dilakukan pada penelitian ini dalam bentuk dokumentasi, angket dan tes. Teknik analisis data yang digunakan dalam penelitian ini yaitu dengan menggunakan skala Likert pada angket, sedangkan untuk mengukur validitas instrumen dengan menggunakan. Hasil penelitian ini adalah karakteristik model pembelajaran dengan menggunakan media pembelajaran berupa video pembelajaran bersubtitle yang digunakan untuk mempermudah pemahaman konsep kalkulus pada mahasiswa normal dan mahasiswa berkebutuhan khusus. Berdasarkan hasil angket maupun tes, diperoleh informasi bahwa secara umum pembelajaran yang diberikan dapat diterima dengan baik oleh semua mahasiswa, khususnya mahasiswa berkebutuhan khusus dengan gangguan pendengaran.
\end{abstract}

Katakunci: Berkebutuhan khusus; video bersubtitle; inovasi pembelajaran.

\begin{abstract}
This study aims to develop an online learning model that is friendly and suitable for students according to special needs. The development of the video-based model used in this study is the ADDIE (Analysis-Design-Develop-Implement-Evaluate) Learning Design model. These product designs include: (1) RPS; (2) teaching materials; (3) Learning Videos; and (4) Learning Evaluation. Data collection techniques used in this study were in the form of documentation, questionnaires and tests. The data analysis technique used in this study is a Likert scale in the questionnaire, while to measure the validity of the instrument using. The results of this study are the characteristics of the learning model using learning media in the form of subtitled learning videos which are used to facilitate understanding the concept of calculus in normal students and students with special needs. Based on the results of questionnaires and tests, information was obtained that in general the learning given was well received by all students, especially students with special needs with hearing loss.
\end{abstract}

Keywords: With special needs; video with subtitles; learning innovation.

\section{Pendahuluan}

Pendidikan inklusi merupakan penggabungan penyelenggaraan pendi- dikan luar biasa dengan pendidikan reguler dalam satu sistem pendidikan yang dipersatukan (Kemendikbud, 2016). 
Pendidikan inklusi adalah penyelenggaraan pendidikan yang menyatukan anak-anak berkebutuhan khusus dengan anak-anak normal pada umumnya untuk belajar (Smith, 2006). Pendidikan inklusif juga mencakup siswa penyandang cacat, siswa dengan kesulitan belajar, dan kelompok marginal lainnya ke sekolah biasa (Ainscow \& Haile-Giorgis, 1999). Selain itu, Pendidikan inklusi juga mengatur hak semua peserta didik dengan beragam kebutuhan untuk mengakses pendidikan di sekolah (Forlin, 2010). Pendidikan inklusi adalah penyelenggaraan pendidikan dan pembelajaran yang memuat mahasiswa berkebutuhan khusus dan mahasiswa normal yang bertujuan untuk pemerataan pendidikan.

Keberhasilan pendidikan inklusi juga bergantung pada keberadaan sistem pendukung, seperti halnya kompetensi guru, sumber daya sekolah, dukungan sosial, dan partisipasi masyarakat (Kantavong, 2017). Selain itu, peran orang tua dan masyarakat penting dalam pelakasnaan pendidikan inklusi yang sukses (Forlin 2012; Sharma,dkk, 2013). Dalam mencapai tujuan pembelajaran pada pendidikan inklusi, guru harus menggunakan berbagai pendekatan pengajaran, bekerja secara kolaboratif, dan menggunakan berbagai metode penilaian (Rouse, 2006). Oleh karena itu, guru harus mampu mendesain pembelajaran untuk mahasiswa yang berkebutuhan khusus demi tercapainya tujuan pembelajaran yang diinginkan.

Desain pembelajaran yang dirancang dapat meliputi beberapa komponen pembelajaran. Komponenkomponen utama dari desain yang dirancang terdiri dari model, metode, materi, media, dan evaluasi (Sunanto \& Hidayat, 2016). Komponen pembelajaran ini harus dilakukan modifikasi agar dapat mengakomodasi dan mengasimilialasi semua keragaman dan sesuai dengan jenis kebutuhan khusus mahasiswa. Hal ini sesuai dengan disarankan oleh Sternberg \& Taylor (1986) yaitu, prosedur pengajaran, materi/isi pembelajaran, dan penggunaan alat yang adaptif.

Penggunaan video sebagai media pembelajaran sudah banyak dilakukan oleh peneliti dianataranya : Batubara \& Ariani (2016); Lasabuda (2017); Ilsa, dkk (2021); dan Nugroho, dkk (2019). Berdasarkan hasil penelitian Ilsa, dkk (2021) diperoleh informasi bahwa video pembelajaran memberikan dampak, pengaruh dan hasil yang sangat baik terhadap aktivitas peserta didik, hal ini sejalan dengan hasil penelitian Nugroho, dkk (2019) yang menemukan fakta bahwa pembelajaran berbasis youtube berpengaruh positif terhadap kemampuan pemahaman konsep, dan lebih baik dari pada pembelajaran konvensional. Senada dengan dua hasil penelitian sebelumnya Batubara \& Aruni (2016) menyatakan bahwa penggunaan video pembelajaran memiliki keunggulan yaitu mudah digunakan dan mampu menjelaskan konten dengan lebih nyata. Berdasarkan beberapa hasil penelitian tersebut terlihat bahwa penggunaan video pembelajaran dapat menjadi salah satu alternatif yang dapat digunakan sebagai media pembelajaran, terlebih pada masa pandemi covid-19 ini yang menuntut semua orang untuk mematuhi protokol kesehatan. Keberadaan peserta didik dengan kebutuhan khusus tentunya perlu diperhatikan sehingga proses pembelajaran yang nantinya dilaksanakan akan ramah bagi peserta didik yang memiliki kebutuhan khusus.

Pengembangan dalam pembelajaran atau bantuan scaffolding yang diberikan pada mahasiswa pada proses pembelajaran khususnya bagi mahasiswa yang berkebutuhan khusus. Anghileri (2006) menyatakan pengajar yang efektif jika mampu memberikan bantuan kepada pebelajar dengan berbagai pendekatan dalam pembelajaran yang mendorong 
keterlibatan aktif pebelajar. Selanjutnya Jannah, dkk (2019) menyatakan bahwa pemberian bantuan (scaffolding) dapat meminimalisasi kesulitan mahasiswa dalam pembelajaran dan membantu memahamkan konsep. Untuk itu perlu adanya pengembangan inovasi dalam pembelajaran yang sesuai dengan kebutuhan khusus yang dimiliki oleh mahasiswa, sehingga pembelajaran yang diberikan ramah dan mudah dimengerti oleh mahasiswa berkebutuhan khusus. Pemberian bantuan (scaffolding) merupakan salah satu inovasi pembelajaran yang dapat digunakan untuk pembelajaran mahasiswa yang berkebutuhan khusus.

Universitas Madura memiliki 11 program studi (prodi) yang terdiri dari pendidikan matematika, pendidikan bahasa Indonesia, Pendidikan Bahasa Inggris, teknik informatika, teknik sipil, peternakan, ekonomi manajeman, akuntansi, Ilmu administrasi, hukum dan teknik industri. Dari 11 prodi tersebut, berdasarkan informasi dari ketua program studi (kaprodi) terdapat beberapa mahasiswa berkebutuhan khusus. Mahasiswa berkebutuhan khusus yang akan menjadi fokus dalam pengembangan model inovasi pembelajaran ini adalah mahasiswa dengan jenis kebutuhan khusus pendengarannya terganggu. Berdasarkan latar belakang dan asesmen kebutuhan yang telah dilakukan peneliti, maka peneliti memutuskan untuk mengembangkan model inovasi pembelajaran mahasiswa berkebutuhan khusus (mbk) berbasis video bersubtitle.

\section{Metode Penelitian}

1. Model Pengembangan

Pengembangan model berbasis video yang digunakan dalam penelitian ini adalah model Desain Pembelajaran ADDIE (Analysis-Design-DevelopImplement-Evaluate). Tahap analisis (Analysis) adalah suatu proses needs assessment (analisis kebutuhan), mengidentifikasi masalah (kebutuhan) dan melakukan analisis tugas (task analyze). Analisis dilakukan pada beberapa prodi di Universitas Madura yang memiliki mahasiswa berkebutuhan khusus. Pada Desain (Design) yang sangat diperhatikan adalah tingkat kesesuaian video dengan jenis kebutuhan khusus subjek penelitian. Pada tahap Develop ini adalah merealisasikan video berdasarkan analisis dan desain sehingga produk yang dihasilkan sesuai dengan kebutuhan dan dapat digunakan secara efektif dan efisien. Selanjutnya dilakukan diimplementasikan dan pada akhrinya dilakukan evaluasi.

2. Desain Produk

Peneliti bersama dengan dosen pengajar matakuliah kalkulus dasar, menyusun rencana pembelajaran yang akan dilaksanakan secara daring. Adapun perangkat pembelajaran yang akan dikembangkan untuk membantu proses pembelajaran bagi mahasiswa yang memiliki keterbatasan pada pendengarannya pada penelitian ini diantaranya: (1) RPS; (2) Materi ajar; (3) Video Pembelajaran Bersubtitle dan (4) Evaluasi Pembelajaran.

3. Validasi dan Implementasi

Sebelum dilaksanakan implementtasi, maka produk yang telah dibuat divalidasi terlebih dahulu untuk selanjutnya dilakukan revisi sesuai dengan hasil validasi maupun FGD yang telah dilaksanakan sebelumnya. Implementasi 1 dan Implementasi 2 dilaksanakan dengan dua kali pertemuan yang melibatkan 35 mahasiswa dengan satu mahasiswa yang memiliki keterbatasan pendengaran. Namun sebelum dilakukan uji coba, terlebih dahulu dilakukan FGD dan validasi terhadap produk yang akan digunakan.

\section{Hasil dan Pembahasan}

1. Analisis kebutuhan 
Dari enam mahasiswa

berkebutuhan khusus yang dimiliki oleh Universitas Madura, peneliti memutuskan untuk mengembangkan model pembelajaran bagi mahasiswa dengan keterbatasan pendengaran. Berdasarkan observasi lebih lanjut terhadap mahasiswa yang bersangkutan, diperoleh informasi dari pihak orang tua bahwa mahasiswa tersebut pendengarannya terganggu sejak kecil. Namun berdasarkan observasi yang kami lakukan, maka mahasiswa ini kami golongkan sebagai gangguan pendengaran tingkat rendah karena masih bisa berkomunikasi meskipun terkadang tidak dapat menangkap maksud dari pembicaraan yang sedang berlangsung.

Berdasarkan jenis kebutuhan khusus yang dialami oleh subjek penelitian, peneliti merancang pengembangan pembelajaran berbasis video yang diupload di youtube dengan memberikan subtitle. Sabila dan Kurniawati (2019), yang menyatakan bahwa pembelajaran disesuaikan dengan karakteristik anak, dengan kata lain jika seorang anak bermasalah dengan pendengarannya maka indera penglihatannya dapat membantunya dalam proses pembelajaran. Sukmawaty (2019) menyatakan bahwa pembelajaran dengan gambar/picture dapat menjadi salah satu alternatif model pembelajaran bagi anak tuna rungu. Dengan pemberian subtitle pada video pembelajaran, tentunya akan memudahkan mahasiswa berkebutuhan khusus dalam hal ini mahasiswa yang mengalami masalah dengan pendengarannya dalam memahami materi pembelajaran secara utuh. Selain itu video pembelajaran yang diupload di Youtube akan mudah diakses oleh mahasiswa, serta dapat ditonton berulang kali sehingga akan memudahkan mahasiswa untuk memahami materi yang diberikan secara komprehensif.
Selain penggunaan media Youtube, peneliti akan menggunakan aplikasi Scratch 2 sebagai media evaluasi. Aplikasi ini sangat cocok bagi mahasiswa terutama mahasiswa yang mengalami gangguan pendengaran, karena aplikasi ini menyediakan visualisasi yang menarik dan tampilan berupa kata-kata yang sangat cocok tentunya bagi mahasiswa yang mengalami gangguan pendengaran. Hal ini sejalan dengan pendapat Suriwati, dkk (2014) yang menyatakan bahwa penggunaan media visual lebih bisa dimengerti oleh peserta didik tuna rungu karena karakter peserta didik tuna rungu lebih mengerti dengan materi yang bersifat kongkrit dan sulit mengerti hal yang bersifat abstrak. Berikut kami sajikan gambar penggunaan media scratch 2 sebagai alat evaluasi belajar bagi mahasiswa.

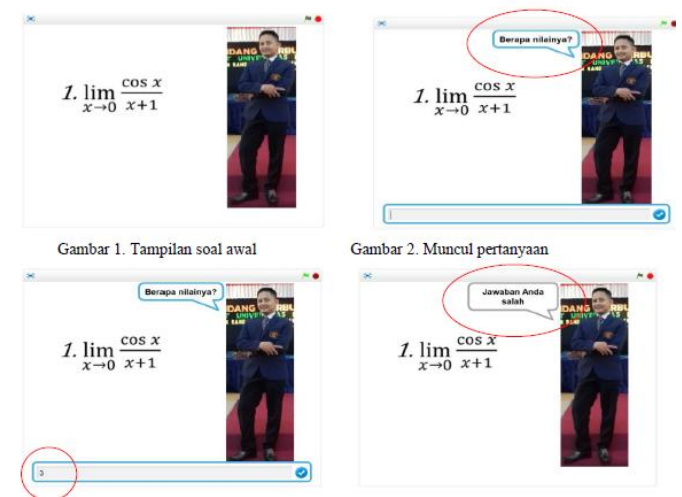

Gambar 1. Tampilan pada aplikasi scratch 2

2. Pengembangan Model

a. Nama Model Pembelajaran Inovatif Model Pembelajaran Inovatif yang dihasilkan oleh peneliti adalah video pembelajaran yang bersubtitle (Bahasa Indonesia) sehingga memudahkan mahasiswa khususnya mahasiswa yang mengalami gangguan pendengaran dalam memahami pembelajaran secara utuh. Nama model pembelajaran inovatif ini adalah "Model Inovasi Pembelajaran Mahasiswa Berkebutuhan Khusus (MBK) Berbasis Video 
Bersubtitle".

b. Spesifikasi Model Pembelajaran Inovatif

Spesifikasi model pembelajaran sebagai bagian yang utuh dalam model direct instruction yaitu:

1) aplikasi zoho form yang digunakan untuk presensi kehadiran mahasiswa, penggunaan aplikasi zoho form memiliki spesifikasi yang lebih baik dibandingkan dengan aplikasi yang lain karena pada aplikasi zoho form mahasiswa dapat memberikan ttd secara virtual dan mudah;

2) video bersubtitle merupakan spesifikasi utama dalam model inovasi pembelajaran bagi $\mathrm{MBK}$ untuk membuat video pembelajaran yang ramah bagi mahasiswa yang memiliki masalah dalam pendengarannya.

3) Aplikasi Scratch 2, digunakan karena memiliki spesifikasi yang cocok bagi mahasiswa yang memiliki masalah dalam pendengarannya. Selain memiliki tampilan visualisasi yang menarik aplikasi ini juga dapat menampilkan tulisan-tulisan yang sangat cocok tentunya bagi mahasiswa yang memiliki masalah dalam pendengarannya.

a. WA grup, juga tetap menjadi pilihan alternatif bagi dosen pengajar dalam melakukan koordinasi dengan siswa. Tentunya komunikasi secara tulis juga sangat ramah bagi mahasiswa yang memiliki masalah pada pendengarannya.

b. Zoom Meeting, tetap menjadi pilihan untuk berinteraksi secara langsung dengan mahasiswa secara umum. Namun demikian bagi mahasiswa yang mengalami gangguan pendengaran tetap dapat melakukan interaksi dengan memanfaatkan menu chat yang disediakan pada Zoom.

\section{Penerapan}

Adapun proses penerapan pembelajaran dengan model inovasi pembelajaran MBK berbasis video bersubtitle, mengikuti alur sebagai berikut:

a. Dosen memulai pembelajaran dengan mengucapkan salam (WA Grup).

b. Selanjutnya dosen memberikan link presensi mahasiswa dengan menggunakan zoho form.

c. Dosen memberikan link video besubtitle kepada mahasiswa, meminta mahasiswa memahami pembelajaran dan menanyakan hal yang belum dipahami dengan berkomentar melalui kolom chat pada Youtube (WA Grup).

d. Mahasiswa menonton video bersubtitle, dan bertanya via chat youtube (Individu).

e. Dosen meminta mahasiswa masuk dalam Zoom Meeting dengan membagikan link Zoom di WA grup

f. Dosen melakukan interaksi dengan mahasiswa secara langsung, serta memberikan evaluasi pada mahasiswa.

4. Hasil Penerapan Model

Penerapan model pembelajaran dilaksanakan melalui implementasi 1 dan implementasi 2 dilanjutkan dengan proses evaluasi. Berikut ini kami paparkan secara rinci hasil penerapan model:

a. Validasi Produk

Produk yang dihasilkan divalidasi oleh dua ahli yaitu ahli di bidang pendidikan matematika dan ahli pada bidang teknologi pendidikan. 
Pelaksanakan validasi dilaksanakan dengan FGD melalui Zoom Meeting. Berikut ini beberapa saran dan masukan dari validator, baik terkait RPS maupun video pembelajaran yang telah dibuat:

1) Aspek yang dinilai : Pewarnaan pada video pembelajaran tidak mengacaukan anda dalam memahami keseluruhan materi

Saran: Diberi green screen lebih oke pak, agar secara visual lebih eye-catching

2) Aspek yang dinilai : Video menggunakan bahasa Indonesia yang baik dan benar

Saran: Translation/transkrip sudah benar, namun terkadang ada miss lead antara suara dan transkrip, mohon cek lagi pak

3) Aspek yang dinilai : Penggunaan font (jenis dan ukuran huruf) pada video sudah sesuai dan mudah dibaca oleh pengguna

Saran : Jika memungkinkan penulisan symbol dicetak miring, seperti $p$ agar membedakan konsepsi Bahasa dan Simbol

4) Pemberian subtitle pada video akan mempermudah mahasiswa dengan kebutuhan khusus pendengaran saat memahami materi pembelajaran.

Saran : Setuju namun alangkah baiknya dperhatikan seperti catatn saya diatas di poin

5) Pada RPS dipaparkan bahwa pelaksanaan pembelajaran dilaksanakan secara daring.
Selanjutnya peneliti melakukan revisi berdasarkan masukan dari para ahli/validator, beberapa saran/masukan dari para ahli/validator dapat dilaksanakan namun ada beberapa masukan atau saran yang tidak bisa dilakukan karena beberapa keterbatasan. Berikut ini gambar FGD yang dlakukan bersama tim Ahli.

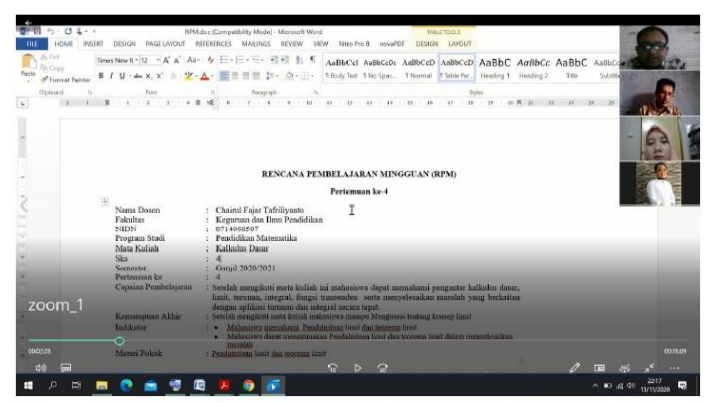

Gambar 2. FGD dengan Validator Via Zoom

b. Implementasi 1

Pelaksanaan

Implementasi pertama berjalan sesuai dengan RPS dan RPM yang telah rencanakan. Implementasi 1 dilaksanakan dengan dua kali pertemuan yaitu pertemuan keempat dan petemuan kelima, berdasarkan hasil rekapitulasi zoho form tercatat pada pertemuan 4 sebanyak 35 mahasiswa mengisi daftar hadir sedangkan pada pertemuan ke 5 sebanyak 33 mahasiswa mengisi daftar hadir. Pada implementasi 1 dibuat dua video pembelajaran bersubtitle masing-masing berdurasi 24.46 menit dan 44.07 menit. Berdasarkan hasil observasi yang dilakukan peneliti ditemukan beberapa kendala yang dihadapi saat implementasi pertama berlangsung diantaranya : (1) gambar dosen pada video pembelajaran kurang matching dengan background, (2) beberapa mahasiswa tidak dapat memberikan komentar pada video 
pembelajaran, karena tidak tersedia kolom komentar di akun youtube mereka, (3) beberapa mahasiswa terkendala jaringan sehingga kesulitan dalam memutar video pembelajaran serta kesulitan pada saat sesi terakhir yaitu pada saat online via Zoom Meeting. Gambar 3 dan 4 adalah video pembelajaran pada implementasi 1.

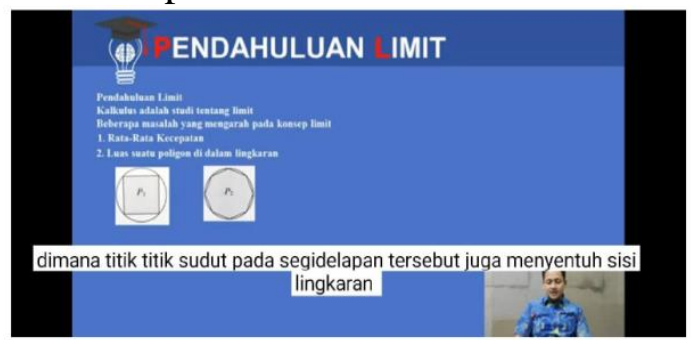

Gambar 3. Tampilan video pada Implementasi 1 (Pertemuan ke-4)

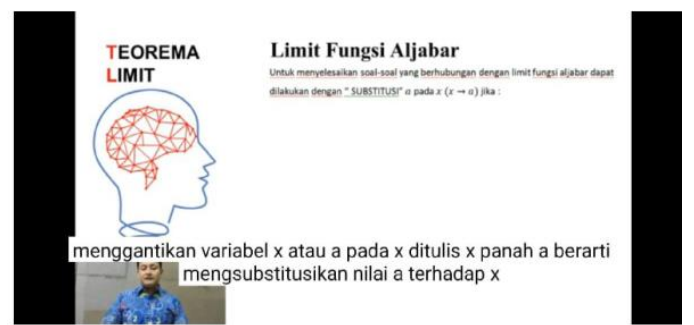

Gambar 4. Tampilan video pada Implementasi 1 (Pertemuan ke-5)

c. Revisi Implementasi 1

Berdasarkan hasil observasi pada implementasi 1, diperoleh beberapa perbaikan-perbaikan yang perlu dilakukan sebelum pelaksanaan implementasi 2 . Beberapa hal yang perlu diperbaiki diantaranya: (1) memperbaiki tampilan dosen pengajar di video sehingga lebih matching, (2) meminta mahasiswa upgrade akun youtube mereka, (3) bagi mahasiswa yang mengalami kendala terkait jaringan agar untuk pertemuan-pertemuan selanjunya disarankan mencari tempat yang memiliki jaringan yang bagus, agar mahasiswa tersebut dapat mengikuti perkuliahan dengan baik. d. Implementasi 2

Pelaksanaan Implementasi kedua berjalan sesuai dengan RPS dan RPM rencanakan. Implementasi 2 dilaksanakan dengan dua kali pertemuan yaitu pertemuan keenam dan petemuan ketujuh, berdasarkan hasil rekapitulasi zoho form tercatat pada pertemuan ke-6 sebanyak 35 mahasiswa mengisi daftar hadir sedangkan pada pertemuan ke-7 sebanyak 35 mahasiswa mengisi daftar hadir. Pada implementasi 2 dibuat dua video pembelajaran bersubtitle masing-masing berdurasi 28.48 menit dan 38.20 menit. Berdasarkan hasil observasi yang dilakukan oleh peneliti ditemukan beberapa kendala yang dihadapi saat implementasi pertama sudah dapat teratasi dengan baik, seperti tampilan pada video pembelajaran sudah dibuat sedemikian rupa sehingga terlihat lebih matching dibandingkan dengan video pada implementasi 1. Gambar 5 dan 6 adalah video pembelajaran pada implementasi 1.

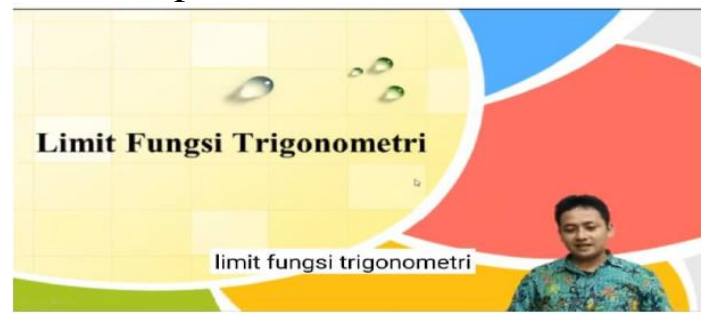

Gambar 5. Tampilan Video pada Implementasi 2 (Pertemuan ke-6)

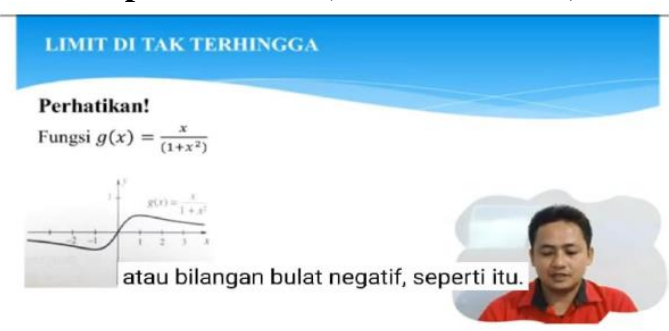

Gambar 6. Tampilan Video pada Implementasi 2 (Pertemuan ke-7) 
e. Evaluasi

Selanjutnya setelah pelaksanaan implementasi 1 dan implementasi 2, berikutnya mahasiswa diminta untuk mengisi Google Form (GF) terkait pembelajaran berbasis video bersubtitle yang telah dilaksanakan. Terdapat 35 mahasiswa yang memberikan respon terhadap GF. Berikut ini rekapitulasi hasil evaluasi terkait pembelajaran yang telah dilaksanakan:

Keterangan Skor:

Skor 1 : Tidak setuju

Skor 2 : Kurang setuju

Skor 3 : Cukup setuju

Skor 4 : Setuju

Skor 5 : Sangat setuju

Tabel 1. Aspek yang Dinilai

\begin{tabular}{|c|c|c|c|c|c|c|c|}
\hline No & Skor & 1 & 2 & 3 & 4 & 5 & $\begin{array}{c}\text { Rata- } \\
\text { rata }\end{array}$ \\
\hline 1 & $\begin{array}{l}\text { Video } \\
\text { pembelajaran } \\
\text { yang dibuat } \\
\text { membantu Anda } \\
\text { dalam } \\
\text { memahami } \\
\text { materi. }\end{array}$ & & 2 & 3 & 8 & 22 & 4,43 \\
\hline 2 & $\begin{array}{l}\text { Isi materi pada } \\
\text { video jelas }\end{array}$ & & & 4 & 5 & 26 & 4,63 \\
\hline 3 & $\begin{array}{l}\text { Video } \\
\text { pembelajaran } \\
\text { mudah diakses }\end{array}$ & 1 & 2 & 3 & 6 & 23 & 4,37 \\
\hline 4 & $\begin{array}{l}\text { Penggunaan } \\
\text { media Scratch } 2 \\
\text { mudah dan } \\
\text { menarik }\end{array}$ & 2 & & 5 & 8 & 20 & 4,26 \\
\hline 5 & $\begin{array}{l}\text { Anda } \\
\text { menginginkan } \\
\text { pembelajaran } \\
\text { berbasis video } \\
\text { seperti pada } \\
\text { matakuliah } \\
\text { kalkulus dasar. }\end{array}$ & & 2 & 5 & 3 & 25 & 4,46 \\
\hline 6 & $\begin{array}{l}\text { Video } \\
\text { pembelajaran } \\
\text { praktis, karena } \\
\text { dapat } \\
\text { downloud atau } \\
\text { diputar berkali- } \\
\text { kali. }\end{array}$ & & & 2 & 5 & 28 & 4,74 \\
\hline 7 & Video & & & & & 1 & 5 \\
\hline
\end{tabular}

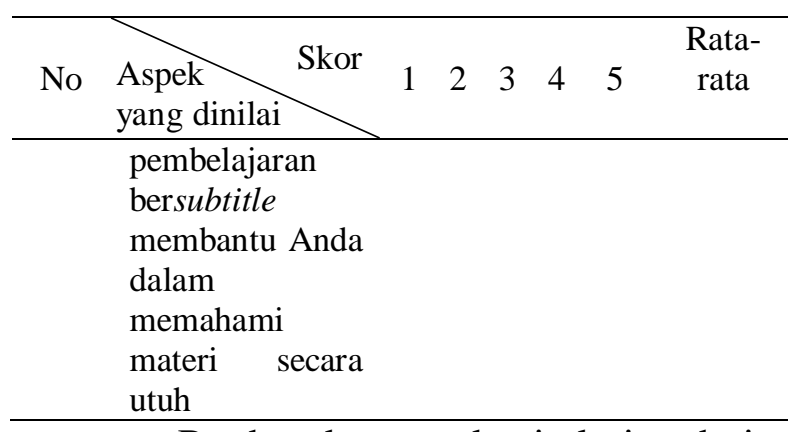

Berdasarkan rekapitulasi dari angket yang diberikan diperoleh informasi bahwa secara umum pembelajaran yang diberikan dapat diterima dengan baik oleh semua mahasiswa, khususnya mahasiswa berkebutuhan khusus dengan gangguan pendengaran. Pertanyaan nomor 1 sampai nomor 6 diberikan kepada semua mahasiswa, sedangkan pertanyaan nomor 7 hanya diberikan kepada mahasiswa dengan gangguan pendengaran. Berdasarkan hasil Rekapitulasi GF dari semua aspek yang dinilai rata-rata skor untuk semua pertanyaan lebih dari 4 yang artinya model pembelajaran yang diberikan menurut mahasiswa dapat diterima dan dapat diaplikasikan pada matakuliah yang lain.

Berdasarkan hasil evaluasi akhir yang dilaksanakan dengan menggunakan Google form berbatas waktu dan diawasi dengan menggunakan Zoom. Diperoleh informasi bahwa sebanyak 7 mahasiswa atau $20 \%$ yang memperoleh nilai $\leq 75$, sebanyak 21 mahasiswa atau $60 \%$ yang memperoleh nilai dengan rentang $75<$ nilai $\leq 90$, dan sisanya sebanyak 7 mahasiswa atau $20 \%$ yang memperoleh nilai dengan rentang $90<$ nilai $\leq 100$. Berdasarkan nilai evaluasi akhir diperoleh informasi bahwa mahasiswa berkebutuhan khusus memperoleh nilai 90, hal ini menjadi salah satu indikator bahwa pembelajaran yang dilaksanakan melalui video pembelajaran bersubtitle mampu dipahami dengan baik oleh semua mahasiswa baik mahasiswa berkebutuhan khusus maupun mahasiswa normal. Hasil ini senada dengan

Pi: Mathematics Education Journal 
penelitian yang dilakukan oleh Suriwati (2014) dimana media visual untuk meningkatkan hasil belajar siswa tuna rungu. Dengan demikian model pembelajaran ini dapat menjadi salah satu alternatif pembelajaran bagi mahasiswa berkebutuhan khusus dalam hal ini mahasiswa yang mengalami masalah dengan pendengarannya.

\section{Kesimpulan}

Berdasarkan hasil dan pembahasan diatas, simpulan pada penelitian ini adalah karakteristik model pembelajaran pada kegiatan ini adalah penggunaan media pembelajaran berupa video pembelajaran bersubtitle yang digunakan untuk mempermudah pemahaman konsep kalkulus pada mahasiswa normal dan mahasiswa berkebutuhan khusus. Video ini dibuat bersubtitle dan di upload di youtube agar mahasiswa berkebutuhan khusus (pendengaran terganggu) yang kesulitan dalam mendengar secara audio dapat memahami konsep-konsep kalkulus melalui subtitle yang ada di dalam video. Selain media ini, kegiatan pembelajaran juga menggunakan media visual scratch yang bertujuan untuk mengevaluasi hasil pembelajaran melalui visualisasi soal dengan gambar yang menarik sehingga membantu mahasiswa khususnya mahasiswa berkebutuhan khusus (MBK).

Model pembelajaran penunjang kegiatan perkuliahan di masa pandemi covid 19 ini menggunakan aplikasi whatsapp, google form dan Zoho. Whatsapp grup digunakan untuk komunikasi dengan mahasiswa terkait kegiatan perkuliahan. Google form digunakan untuk membuat evaluasi secara online serta membuat angket evaluasi terkait model pembelajaran. Sedangkan Zoho Form diguanakan sebagai alat presensi online bagi mahasiswa yang dapat dilengkapi dengan tanda tangan virtual mahasiswa.

\section{Ucapan Terimakasih}

$\begin{array}{ccc}\text { Ucapan } & \text { terima } & \text { kasih kami } \\ \text { sampaikan } & \text { kepada } & \text { Direktorat }\end{array}$ Pembelajaran dan Kemahasiswaan Direktorat Jendral Pendidikan Tinggi Kementerian Pendidikan dan Kebudayaan yang telah memberikan kesempatan kepada Universitas Madura khususnya prodi pendidikan matematika dan memberikan bantuan dana inovasi pembelajaran dan teknologi bantu (teknologi asistif) untuk mahasiswa berkebutuhan khusus di perguruan tinggi tahun 2020. Ucapan terima kasih juga kami sampaikan kepada Rektor Universitas Madura yang telah memberikan dukungannya baik berupa dana pendamping hibah maupun segala kebijakan yang disusun dalam rangka memberikan pelayanan yang terbaik bagi mahasiswa berkebutuhan khusus (MBK).

\section{References}

Anghileri, J. (2006). Scaffolding Practices That Enhance Mathematics Learning. Journal of Mathematics Teacher Education, 9,33-52.

Ainscow, M., \& Haile-Giorgis, M. (1999). Educational arrangements for children categorized ashaving special needs in central and Eastern Europe. European Journal of Special Needs Education, 14(2),103-121.

Batubara, H.H., \& Ariani, D.N. (2016). Pemanfaatan Video sebagai Media Pembelajaran Matematika SD/MI. Jurnal Madrasah Ibtidaiyah 2(1),47-66.

Forlin, C. (2010). Teacher education reform for enhancing teachers' preparedness forinclusion. International Journal of Inclusive 
Education, 14(7),649-653. doi: 10.1080/13603111003778353.

Forlin, C. (2012). Diversity and its challengers. In future directions for inclusive teacher education: An International Perspective, edited by C. Forlin, 83-92. Abingdon: Routledge.

Ilsa, A., Farida, Harun, M. (2021). Pengembangan Video Pembelajaran dengan Menggunakan Aplikasi PowerDirector 18 di Sekolah Dasar. Jurnal Basicedu, 5(1),288-300.

Jannah, U. R., Saleh, H., \& Wahidah, A. (2019). Scaffolding untuk Pembelajaran Matematika di Kelas Inklusi. JKPM (Jurnal Kajian Pendidikan Matematika), 5(1),6172.

Kantavong, P. (2017). Understanding inclusive education practices in schools under localgovernment jurisdiction: a study of Khon Kaen Municipality in Thailand. International Journal of Inclusive Education, 22(4):1-20. doi: 10.1080/13603116.2017.1412509.

Kemendikbud. (2016). Permendikbud No 020 tahun 2016 Tentang Standar Kompetensi Lulusan Pendidikan Dasar Dan Menengah. Jakarta: Kemendikbud.

Lasabuda, N. E. (2017). Pengembangan Media Youtube dalam Pembelajaran Matematika (suatu penelitian di smk kesehatan bakti nusantara gorontalo). Jurnal Riset dan Pengembangan Ilmu Pengetahuan, 2(2), 270-275.

Nugroho, K.U.Z., Widada, W., Zamzaili., \& Herawaty, D. (2019). Pemahaman Konsep Matematika melalui Media Youtube dengan Pendekatan Etnomatematika. Jurnal Pendidikan Matematika Raflesia 4(1),96-106.
Rouse, M. (2006). Enhancing Effective Inclusive Practice: Knowing, Doing and Believing. Kairaranga, 7, 8-13.

Sabila, H., \& Kurniawati, F. (2019). Parental Attitudes of Preschool Children toward Students with Special Needs in Inclusive and Non-Inclusive Kindergartens: A Comparative Study. In 2nd International Conference on Intervention and Applied Psychology (ICIAP 2018) (pp. 602609). Atlantis Press.

Sharma, U., C. Forlin, J. Deppeler, and G. X. Yang. (2013). Reforming teacher education forinclusion in developing countries in the Asia Pacific Region. Asian Journal of Inclusive Education 1(1),3-16.

Smith, J. David. (2006). Inklusi, Sekolah Ramah untuk Semua. Bandung: Penerbit Nuansa.

Sternberg, L., \& Taylor, R. L. (1986). Exceptional Children: Integrating Research and. Teaching. New York: Springer-Verlag.

Sunanto, J., \& Hidayat, H. (2017). Desain Pembelajaran Anak Berkebutuhan Khusus dalam Kelas Inklusif. JASSI ANAKKU, 17(1): 47-55.

Sukmawaty, W.E.P. (2019). Model Pembelajaran Untuk Anak Tunarungu pada Mata Kuliah Tata Busana. The 2nd ICODIE Proceedings, 3-4 December 2019, 111-124.

Suriwati, L.M., Nilakusmawati, D.P.E., Sumarjaya, I.W. 2014. Efektivitas Pembelajaran dengan Media Visual untuk Meningkatkan Hasil Belajar Siswa Tuna Rungu Pokok Bahasan Pecahan Senilai. Seminar Nasional Matematika, Universitas Udayana Bali Denpasar 6 November 2014, 165-170. 